\title{
Phase formation and thermal stability of ultrathin nickel-silicides on $\mathrm{Si}(100)$
}

\author{
K. De Keyser ${ }^{1, a)}$ C. Van Bockstael, ${ }^{1}$ R. L. Van Meirhaeghe, ${ }^{1}$ C. Detavernier, ${ }^{1}$

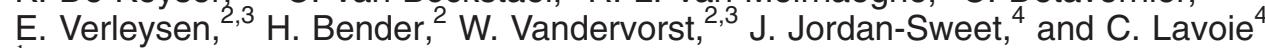 \\ ${ }^{1}$ Department of Solid State Physics, Ghent University, Krijgslaan 281/S1, B-9000 Gent, Belgium \\ ${ }^{2}$ IMEC, Kapeldreef 75, B-3001 Leuven, Belgium \\ ${ }^{3}$ Instituut voor Kern-en Stralingsfysica, K. U. Leuven, Celestijnenlaan 200D, B-3001 Leuven, Belgium \\ ${ }^{4}$ IBM T.J. Watson Research Center, P.O. Box 218, Yorktown Heights, New York 10598, USA
}

(Received 24 November 2009; accepted 18 March 2010; published online 27 April 2010)

\begin{abstract}
The solid-state reaction and agglomeration of thin nickel-silicide films was investigated from sputter deposited nickel films $(1-10 \mathrm{~nm})$ on silicon-on-insulator (100) substrates. For typical anneals at a ramp rate of $3{ }^{\circ} \mathrm{C} / \mathrm{s}, 5-10 \mathrm{~nm} \mathrm{Ni}$ films react with silicon and form NiSi, which agglomerates at $550-650{ }^{\circ} \mathrm{C}$, whereas films with a thickness of $3.7 \mathrm{~nm}$ of less were found to form an epitaxylike nickel-silicide layer. The resulting films show an increased thermal stability with a low electrical resistivity up to $800{ }^{\circ} \mathrm{C}$. (C) 2010 American Institute of Physics. [doi:10.1063/1.3384997]
\end{abstract}

Nickel-silicides are currently used as contacting materials in state-of-the-art microelectronic devices. ${ }^{1,2}$ Feature size has shrunk to a few tens of nanometers, and for nickel monosilicide (NiSi) layers, this results in a particularly severe tendency to agglomerate, ${ }^{3}$ leading to a large increase in the electrical resistance of the contact, and an increased mobility of the nickel as it starts to move on the defects, both resulting in a low yield. Since the agglomeration of thin films is driven by a minimization of interface energy, it is expected that thinner films will agglomerate faster (i.e., have a lower agglomeration temperature). ${ }^{4}$ In this letter, we show that this holds true only for films with a thickness of at least $5 \mathrm{~nm}$ (as-deposited thickness of the nickel layer), while for thinner layers the resulting nickel-silicide layer is much more resistant to agglomeration.

Nickel films with a thickness between 1 and $10 \mathrm{~nm}$ were sputter deposited onto lightly p-doped $(\rho=14-22 \Omega \mathrm{cm})$, Radio Corporation of America (RCA) cleaned, and HF dipped silicon-on-insulator substrates, with a top layer of 117 $\mathrm{nm}$ of $\mathrm{Si}$ (100). The deposition chamber was first evacuated to $10^{-4} \mathrm{~Pa}$ during deposition, the samples were mounted on a rotating carousel to ensure a uniform deposition thickness. An argon pressure of $0.5 \mathrm{~Pa}$ and a sputtering power of $100 \mathrm{~W}$ were used, resulting in a deposition rate of $0.04 \mathrm{~nm} / \mathrm{s}$. After deposition, the samples were annealed in a high-purity $\mathrm{He}$ atmosphere, from 100 to $850{ }^{\circ} \mathrm{C}$ at a rate of $3{ }^{\circ} \mathrm{C} / \mathrm{s}$, and the surface roughness (using laser light scattering, recording the intensity of nonspecular reflection of the laser light), and the sheet resistance (using a four point probe) were recorded in situ. The thickness of both the as-deposited and annealed films was determined using x-ray reflectivity and cross section transmission electron microscopy, resulting in the reported thicknesses with a precision of $\pm 0.2 \mathrm{~nm}$.

An overview of the in situ sheet-resistance is shown in Fig. 1. All of the samples with more than $3.7 \mathrm{~nm}$ of nickel $(6,8$, and $10 \mathrm{~nm}$ are shown), exhibit a sheet resistance qualitatively similar to what was previously reported ${ }^{5}$ for $10 \mathrm{~nm}$ layers of nickel on $\mathrm{Si}$ (100); a complex phase sequence of high-resistive metal rich nickel-silicides at low temperatures, and the formation of the low-resistive $\mathrm{NiSi}$ phase at

${ }^{a)}$ Electronic mail: koen.dekeyser@ugent.be.
$400-450{ }^{\circ} \mathrm{C}$. This layer then agglomerates at $550-650{ }^{\circ} \mathrm{C}$, leading to the observed increase in sheet resistance. In contrast, for the thinner films ( 2 and $3.7 \mathrm{~nm}$ are shown) no agglomeration below $800{ }^{\circ} \mathrm{C}$ is observed, as the resistance stays low. This was corroborated with scanning electron microscopy (SEM) top-view images. The $6 \mathrm{~nm}$ film exhibits severe agglomeration when annealed to $650{ }^{\circ} \mathrm{C}$ [Fig. 2(a)], while the SEM images recorded on a $3.7 \mathrm{~nm}$ film annealed to $650{ }^{\circ} \mathrm{C}$ [Fig. 2(b)] and $850{ }^{\circ} \mathrm{C}$ [Fig. 2(c)] reveal little signs of agglomeration.

The $3.7 \mathrm{~nm} \mathrm{Ni}$ and $6 \mathrm{~nm} \mathrm{Ni}$ samples were further analyzed. High resolution $\mathrm{x}$-ray pole figures were recorded at the X20A beam line of the National Synchrotron Light Source at Brookhaven National Laboratory, using a high dynamic range linear detector, and synchrotron radiation with a wavelength of $0.1546 \mathrm{~nm} .640$ pole figures in a $2 \theta$ range of $29.2^{\circ}-62.6^{\circ}$ were recorded, using a step size in $\phi$ (the rotation of the sample about its normal) and $\chi$ (the tilting of the sample) of $0.6^{\circ}$. Electron backscatter diffraction (EBSD) measurements were carried out using an HKL/Oxford Instruments Channel 5 system, mounted on an FEI Quanta 200F field emission gun scanning electron microscope, at $7.5 \mathrm{kV}$. High resolution transmission electron microscopy (HRTEM), nanobeam diffraction (NBD), and energy dispersive x-ray spectroscopy (EDS) measurements were carried out on a Tecnai F30 microscope.

The pole figures recorded on the sample made by heating a $6 \mathrm{~nm}$ film to $600{ }^{\circ} \mathrm{C}$ at $3{ }^{\circ} \mathrm{C} / \mathrm{s}$ reveal the typical ax-

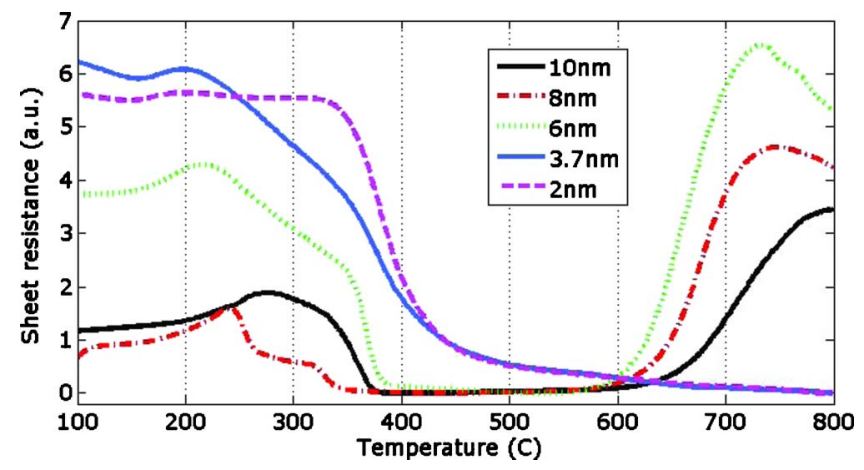

FIG. 1. (Color online) In situ sheet resistance as a function of temperature and thickness for thin nickel films. 

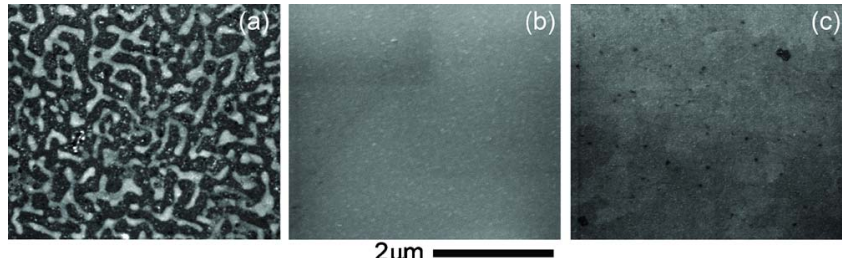

FIG. 2. (Color online) Top view SEM images of (a) a $6 \mathrm{~nm}$ film annealed to $650{ }^{\circ} \mathrm{C}$, showing severe agglomeration, (b) a uniform $3.7 \mathrm{~nm}$ film annealed to $650{ }^{\circ} \mathrm{C}$, and (c) a $3.7 \mathrm{~nm}$ film annealed to $850{ }^{\circ} \mathrm{C}$.

iotaxy lines, ${ }^{6}$ at the $2 \theta$ values corresponding to $\mathrm{NiSi}^{7}$ The pole figure for a $d$-spacing of $0.192 \mathrm{~nm}$, or $2 \theta=47.3^{\circ}[\mathrm{NiSi}$ $\{202\}$ and $\{211\}]$ is shown in Fig. 3(a). Quenches at 350, 450, 600 , and $850{ }^{\circ} \mathrm{C}$ were made for the $3.7 \mathrm{~nm}$ film, and pole figures were recorded; axiotaxy lines are no longer visible, but instead a series of isolated spots appear, suggesting an epitaxial relationship between the film and the substrate [Fig. 3(b)]. Only in the range of $2 \theta$ between $46^{\circ}$ and $48^{\circ}$, diffracted $\mathrm{x}$-rays are detected. However, due to the limited thickness of the film, the diffracted $x$-ray intensity is very low, and the determination of the $2 \theta$ values has a large uncertainty. This makes it difficult to determine an exact $2 \theta$ value and hence determine the phase present. However, the fact that only a few spots are visible, at only a few $2 \theta$ values suggests that it is a high symmetry phase, probably hexagonal or cubic. In addition, the strongest poles coincide with the $\mathrm{Si}\{115\}$ poles of the substrate, indicating a preferential alignment of the layer to these planes.

The samples were also investigated using EBSD, which allows to discriminate between crystal phases with different symmetry (Laue group) or lattice parameters. No EBSD patterns could be recorded on the $6 \mathrm{~nm}$ sample, due to the small grain size of NiSi in these films. ${ }^{8,9}$ However, on the $3.7 \mathrm{~nm}$ samples, we did observe very clear EBSD patterns, which are shown in Fig. 4. The as-deposited sample shows no EBSD pattern [Fig. 4(a)], which confirms that the silicon substrate is covered. At $350{ }^{\circ} \mathrm{C}$ (at which the resistance of the film has started to drop) a weak pattern appears showing a distinctive sixfold symmetry [Fig. 4(b)]. At $600{ }^{\circ} \mathrm{C}$ [Fig. 4(c)] and $850{ }^{\circ} \mathrm{C}$ [Fig. 4(d)] the pattern has become more clear, most likely from an improved crystallinity of the phase. Of the currently known nickel-silicides, the pattern was best fitted as a hexagonal phase, and the simulation when using the $\theta$-nickel-silicide structure is shown in Fig. 4(e). Fitting a cubic phase, like $\mathrm{NiSi}_{2}$, also leads to a good agreement, however three fainter bands are missing in the pattern [indicated with dotted lines on a reference cubic pat-

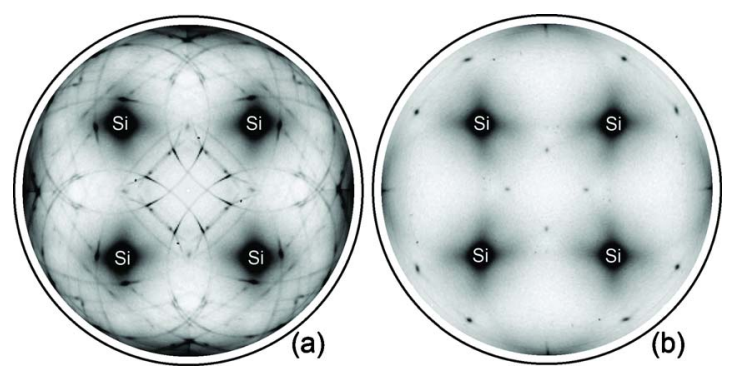

FIG. 3. (Color online) Subfigure (a) pole figure, with $d=0.192 \mathrm{~nm}$, recorded on the $6 \mathrm{~nm} \mathrm{Ni}$ film, after anneal at $600{ }^{\circ} \mathrm{C}$, showing the $\{202\}$ and $\{211\}$ poles. Subfigure (b) pole figure recorded on the $3.7 \mathrm{~nm}$ Ni film, after an anneal at $600{ }^{\circ} \mathrm{C}$.

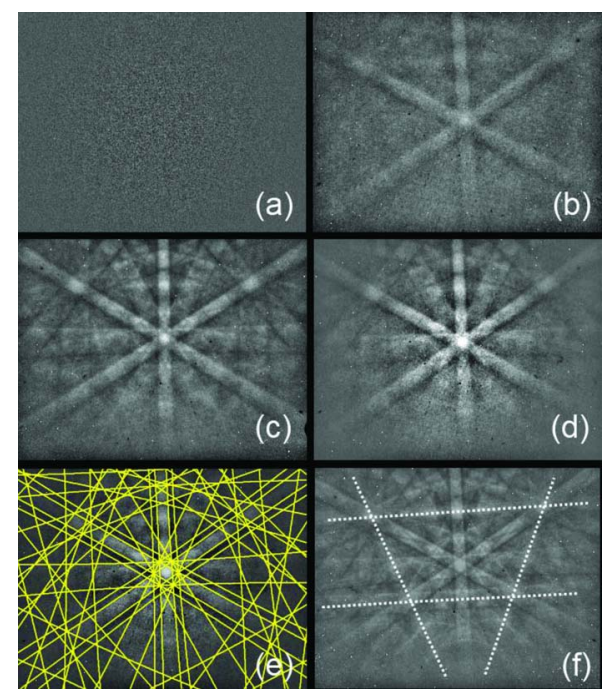

FIG. 4. (Color online) EBSD patterns recorded on a $3.7 \mathrm{~nm}$ Ni film, as deposited (a), and after annealing to (b) $350{ }^{\circ} \mathrm{C}$, (c) $600{ }^{\circ} \mathrm{C}$ and (d) $850{ }^{\circ} \mathrm{C}$. Subfigure (e) shows the simulated EBSD pattern for the $\theta$-phase, while subfigure (f) shows a cubic EBSD pattern, where the additional bands compared to the hexagonal pattern are indicated with dotted lines.

tern in Fig. 4(f)]. The EBSD results therefore seem to suggest a hexagonal symmetry in the layer.

Cross section TEM images were recorded on the asdeposited $3.7 \mathrm{~nm}$ Ni films [Fig. 5(a)], and after anneals to $350{ }^{\circ} \mathrm{C}$ [Fig. 5(b)] and $600{ }^{\circ} \mathrm{C}$ [Fig. 5(e)]. The as-deposited layer was found to be an amorphous mixture of $\mathrm{Ni}$ and $\mathrm{Si}$, over the whole thickness range. This is due to the sputter deposition of the $\mathrm{Ni}$, which causes the creation of an intermixing layer. EDS indicated a $47.2 \pm 0.4 \% \mathrm{Ni}$ contents. At the interface, a very thin crystalline layer with vertical planes of atoms ( $d$-spacing of $0.19 \mathrm{~nm}$ ) is already visible.

After the anneal to $350{ }^{\circ} \mathrm{C}$ [Fig. 5(b)], the layer has become crystalline, with a flat interface, and its thickness has increased to $4.4 \mathrm{~nm}$, and the layer (EDS) was now found to contain $52.8 \pm 0.4 \% \mathrm{Ni}$. The vertical planes, which match the Si $\{220\}$ planes extend through the whole layer, and planes with an inclination of $20^{\circ}$ to the interface have become vis-
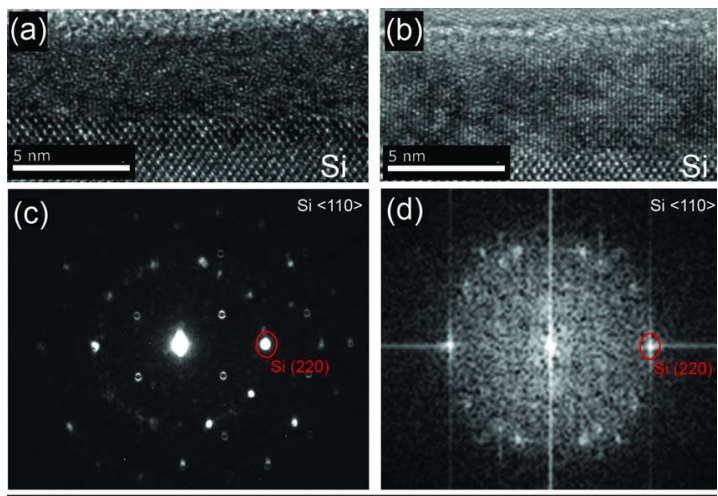

(e)

FIG. 5. (Color online) Cross section HRTEM images on (a) the as deposited $3.7 \mathrm{~nm}$ thick Ni layer and (b) after an anneal to $350{ }^{\circ} \mathrm{C}$. (c) shows the NBD image of the silicide at $350{ }^{\circ} \mathrm{C}$. In (d), the Fourier transform of picture (b) is shown, indicating the orientation of the atom layers in the silicide. After annealing to $600{ }^{\circ} \mathrm{C}$, the layer is no longer flat, and separate grains become visible (e). 
ible [Figs. 5(b) and 5(d)]. A NBD pattern was collected [Fig. $5(\mathrm{c})]$ and is in good agreement with the Fourier transform of the cross section [Fig. 5(d)].

The analysis of the combination of the EDS, TEM, EBSD, and pole figure data showed that no single epitaxy of the currently know nickel-silicides can explain all of the data. This means that we are witnessing a new nickel-silicide phase and/or the layer is not purely epitaxial, but consists of small (a few nanometer) domains which share the alignment of a series of atomic planes, notably the vertical planes, and those with an inclination of $20^{\circ}$ to the interface. This would result in all of these domains contributing to the diffraction pattern of the layer, as they will be averaged over the whole thickness of the TEM sample.

After an anneal to $600{ }^{\circ} \mathrm{C}$, the TEM cross section [Fig. $5(\mathrm{e})]$ shows that parts of the interface are no longer perfectly flat; in some places, the layer thickness has increased, and separate grains become visible. TEM diffraction on these grains (not shown here) shows that both $\theta$-nickel-silicide, and $\mathrm{NiSi}_{2}$ grains have been formed.

Combining the x-ray pole figures and TEM data, we can conclude that at thicknesses of $3.7 \mathrm{~nm}$ or below, the deposited film is no longer pure $\mathrm{Ni}$, but a mixture of $\mathrm{Ni}$ and $\mathrm{Si}$. This changes the phase sequence, and results in the formation of an epitaxylike phase, which might consist of small domains which have some shared atomic planes. This shared symmetry is what is visible in the pole figures. The location of the spots on the pole figure at $\chi=20^{\circ}$ and their corresponding $d$-spacing $(0.19 \mathrm{~nm})$ are indeed consistent with the TEM results. During subsequent annealing, part of this layer is converted to $\theta$-nickel-silicide and $\mathrm{NiSi}_{2}$, keeping the sheet resistance low, but also resulting in a rougher interface. This presents a significant problem that must be overcome before these layers can be used in a device.

The origin and exact structure of the epitaxylike phase is at the moment unclear. A similar pole figure as in Fig. 3(b) has been reported by Gaudet et al. ${ }^{10}$ as a transient phase in the $\mathrm{Ni} / \mathrm{Si}$ reaction in $10 \mathrm{~nm}$ films, which seems to indicate that this phase occurs in all $\mathrm{Ni} / \mathrm{Si}$ films, but is unstable in contact with pure $\mathrm{Ni}$, as it is quickly converted to NiSi. In addition, we have reported before that unexpected phases can occur in the $\mathrm{Ni} / \mathrm{Si}$ system, such as $\theta$-nickel-silicde which crystallizes from a $\mathrm{Ni}(60 \%) / \mathrm{Si}(40 \%)$ mixture, ${ }^{11,12}$ even though this phase is not one of the thermodynamically stable nickel-silicides at room temperature, the slow kinetics prevent it from being decomposed, resulting in the observed metastability. As the as-deposited layer of the $3.7 \mathrm{~nm}$ film is also a mixture of $\mathrm{Ni}$ and $\mathrm{Si}$, a similar process might be occurring here. However, the exact phase that forms from this layer upon annealing can be different, as the $\mathrm{Ni} / \mathrm{Si}$ ratio of the spontaneous intermixing layer in the ultrathin films is different from the $\mathrm{Ni}(60 \%) / \mathrm{Si}(40 \%)$ case we studied before.

In conclusion, we found that there exists a specific thickness for sputter-deposited nickel films, which determines the phase sequence and the formation of the low resistive phase which is formed during a subsequent ramp anneal. Films with $3.7 \mathrm{~nm}$ of nickel or less form a low resistive phase consisting of an epitaxylike phase. This layer exhibit a high thermal stability, and gets converted to $\mathrm{NiSi}_{2}$ and $\theta$-nickel silicide at higher temperatures, resulting in low electrical resistivity up to $800{ }^{\circ} \mathrm{C}$. The occurrence of this phase is likely caused by the interfacial intermixing layer, resulting from the sputter deposition.

The authors would like to thank D. P. Siddons for his assistance with the high dynamic range linear $\mathrm{x}$-ray detector at Brookhaven National Laboratory. K. De Keyser thanks the Fonds voor Wetenschappelijk Onderzoek Vlaanderen (FWO) for financial support. Use of the NSLS, Brookhaven National Laboratory, was supported by the U.S. Department of Energy, Office of Basic Energy Sciences (Contract No. DEAC02-98CH10886).

${ }^{1}$ C. Lavoie, F. M. d'Heurle, C. Detavernier, and C. Cabral, Microelectron. Eng. 70, 144 (2003).

${ }^{2}$ A. Lauwers, J. A. Kittl, and M. J. H. Van Dal, Mater. Sci. Eng., B 114115, 29 (2004).

${ }^{3}$ E. G. Colgan, J. P. Gambino, and Q. Z. Hong, Mater. Sci. Eng. R. 16, 43 (1996).

${ }^{4}$ O. Chamirian, J. A. Kittl, A. Lauwers, O. Richard, M. van Dal, and K. Maex, Microelectron. Eng. 70, 201 (2003).

${ }^{5}$ D. Deduytsche, C. Detavernier, R. L. Van Meirhaeghe, and C. Lavoie, J. Appl. Phys. 98, 033526 (2005).

${ }^{6}$ C. Detavernier, J. Jordan-Sweet, and C. Lavoie, J. Appl. Phys. 103, 113526 (2008).

${ }^{7}$ F. d'heurle, C. S. Petersson, J. E. E. Baglin, S. J. Laplaca, and C. Y. Wong, J. Appl. Phys. 55, 4208 (1984).

${ }^{8}$ K. De Keyser, C. Detavernier, and R. L. Van Meirhaeghe, Appl. Phys. Lett. 90, 121920 (2007).

${ }^{9}$ F. J. Humphreys, J. Mater. Sci. 36, 3833 (2001).

${ }^{10}$ S. Gaudet, C. Coia, P. Desjardin, and C. Lavoie, J. Appl. Phys. (to be published)

${ }^{11}$ K. De Keyser, C. Van Bockstael, C. Detavernier, R. L. Van Meirhaeghe, J. Jordan-Sweet, and C. Lavoie, Electrochem. Solid-State Lett. 11, H266 (2008).

${ }^{12}$ M. Ellner, S. Heinrich, M. K. Bhargava, and K. Schubert, J. LessCommon Met. 66, 163 (1979). 